\title{
The role of phonological and orthographic awareness in learning to read among Grade 1 and 2 students in Taiwan
}

Article

Accepted Version

Hsuan, C.-H., Tsai, H. J. and Stainthorp, R. (2018) The role of phonological and orthographic awareness in learning to read among Grade 1 and 2 students in Taiwan. Applied Psycholinguistics, 39 (1). pp. 117-143. ISSN 1469-1817 doi: https://doi.org/10.1017/S0142716417000194 Available at https://centaur.reading.ac.uk/72050/

It is advisable to refer to the publisher's version if you intend to cite from the work. See Guidance on citing.

To link to this article DOI: http://dx.doi.org/10.1017/S0142716417000194

Publisher: Cambridge University Press

All outputs in CentAUR are protected by Intellectual Property Rights law, including copyright law. Copyright and IPR is retained by the creators or other copyright holders. Terms and conditions for use of this material are defined in the End User Agreement.

www.reading.ac.uk/centaur 
Central Archive at the University of Reading

Reading's research outputs online 
The Role of Phonological and Orthographic Awareness in Learning to Read among Grade 1 and 2 Students in Taiwan

Short Title: Phonological \& Orthographic Awareness and Reading

Chung-Hui Hsuan ${ }^{1}$, Henry J Tsai ${ }^{2}$, Rhona Stainthorp ${ }^{3}$

${ }^{1}$ Department of Early Childhood Education, National Chiayi University, Taiwan (chunghui2002@mail.ncyu.edu.tw)

${ }^{2}$ Department of Health and Nutrition Biotechnology, Asia University, Taiwan (henrytsai@asia.edu.tw)

${ }^{3}$ Institute of Education, University of Reading, UK

(r.w.stainthorp@reading.ac.uk)

Correspondence sent to: Henry J Tsai (henrytsai@asia.edu.tw)

Acknowledgement:

The authors would like to thank those young students and their parents for participating in this research. This research was supported by the Ministry of Science and Technology, Taiwan (MOST 105-2410-H-415-019, to HSUAN) and Asia University/China Medical University Hospital joint grant (ASIA-105-CMUH-21 to TSAI). 


\begin{abstract}
The role of phonological and orthographic awareness on Chinese character reading from grade 1 to 2 was investigated with 112 Taiwanese children. Phonological awareness (onset, rime and tone), rudimentary orthographic awareness (character configuration and structure knowledge) and character reading were assessed in each grade. The strategy of learning to read novel characters using regular or sophisticated orthography-to-phonology correspondence (OPC) rules or character mapping was tested in grade 2. Our results suggested that (1) phonological and orthographic awarenesses are important in grade 1, and tone awareness in grade 1 uniquely predicts character reading in grade 2; (2) the use of sophisticated OPC rules and mapping strategy are crucial for character reading in grade 1 and 2. Additionally, phonological and rudimentary orthographic awareness are important for using sophisticated orthographic strategy when learning to read novel characters.
\end{abstract}




\section{Introduction}

Many studies have been devoted to understanding the developmental processes of orthography-phonology in Chinese character reading (Anderson, $\mathrm{Li}, \mathrm{Ku}, \mathrm{Shu}, \&$ Wu, 2003; He, Wang, \& Anderson, 2005; Ho \& Bryant, 1997; a; b; Shu \& Anderson, 1999; Shu, Anderson, \& Wu, 2000). Many of them have been focused on the processes of using Chinese orthography-to-phonology correspondence rules (i.e., the OPC rules). The application of OPC rules entails the skill of segmenting a Chinese character and then retrieving the phonological information from its functional component. It is suggested that using OPC rules to read is a critical threshold for becoming a skilled reader (Anderson et al., 2003; Shu et al., 2000). However, since a character with no embedded phonological information can only be learned by mapping its orthography to its pronunciation directly, learning to pair a visual symbol with its corresponding pronunciation had also been demonstrated important for reading acquisition (Chow, 2014; Li, Shu, McBride-Chang, Liu, \& Xue, 2009).

Children in Taiwan are instructed to read Chinese characters explicitly with a phonological tool, Tzuyin, during grade 1. Tzuyin is comprised of 37 phonetic symbols dictating the pronunciations of Chinese characters sub-syllabically with 4 notations signaling the tones. The tone is a suprasegmental feature that changes the pitch of the syllable. Because Tzuyin is labeled alongside Chinese characters, Taiwanese children develop phonological awareness quickly, which helps character reading during the first year of learning to read (Huang \& Hanley, 1997). Taiwanese children in grades 1 and 2 use Tzuyin system to symbolize the pronunciation of each new character, while orthographic knowledge is not taught explicitly until grade 3. Despite this learning approach, most Taiwanese children develop a skill of Chinese orthography implicitly through literacy exposure and learn to read novel characters 
based on OPC rules in grade 2 (Tsai \& Nunes, 2003). This phenomenon implies that phonological awareness and orthographic knowledge develop hand in hand along with reading development in the first two years of learning to read. However, little is known about how phonological awareness or orthographic knowledge contributes to character reading along the developmental stages. Therefore, this study aims to examine the developmental relationships among phonological awareness, orthographic knowledge and character reading from grade 1 to grade 2, particularly those who has learned reading solely through the phonological approach but somehow learned the orthographic knowledge implicitly.

\section{Orthographic awareness and Chinese character reading development}

Chinese characters are composed of various strokes, such as, \, 一, | , 」, - , J , ` , \, which form 440 recurrent stroke patterns (Huang, 2003), e.g., 一, 十,

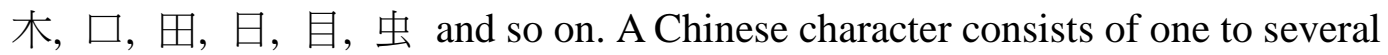
stroke patterns arranged in a square format. With daily exposure to literacy, Chinese young children proceed gradually from logographic readers (Ehri, 1991) toward being aware of the segments of stroke patterns and their spatial arrangement within a character (Ho, Yau, \& Au, 2003). Each Chinese character maps onto one syllable; while stroke patterns embedded in each character do not systematically correspond to sub-syllabic units like the correspondence of graphemes to phonemes in the alphabetic system. Therefore, stroke patterns, also called graphic units, are the basic units for visual recognition in Chinese characters for both skilled readers (Chen, Allport, \& Marshall, 1996) and young children (Chan, 1996; Chan \& Nunes, 1998; Qian, Song, Zhao, \& Bi, 2015).

It has been suggested that Chinese children begin to take advantage of recurrent stroke patterns and their positional constrains in Chinese characters to read before 
grade 2 (Hung, 1997; Pak et al., 2005; Siok \& Fletcher, 2001). Siok and Fletcher (2001) used a component search task that required children to detect a stroke pattern (e.g., $\square$ ) embedded in varied positions of different Chinese characters, and found that $1^{\text {st }}$ and $2^{\text {nd }}$ graders could achieve $69 \%$ and $85 \%$ correct recognition, respectively. Pak et al. (2005) reported early graders' ability to make use of familiar stroke patterns to learn to write novel characters using a delayed copying method. They found that first graders had better performance on copying novel characters that are consisted of familiar stroke patterns as compared to those with unfamiliar ones. Hung (1997) investigated the development of structure knowledge in Chinese characters among primary school children. In her study, children were presented with pseudocharacters and non-characters side by side and asked to differentiate them by referring to the positional constraints of stroke patterns. Those pseudocharacters were constructed to conform to the positional rules by two stroke patterns (e.g., 女井, in which the semantic radical 女 only appeared on the left side of a character) while the noncharacters violated these rules (e.g., 反片, in which the semantic radical 片 never appeared on the right hand side). Hung (1997) found that $83 \%$ of second graders can attain a score significantly above the random average, suggesting most of the second graders have had learned the positional constraints of stroke patterns/semantic radicals. The rudimentary orthographic knowledge in configuration and structure not only plays an important role in character reading at the early stage of learning to read (McBride-Chang \& Ho, 2005; Siok \& Fletcher, 2001; Wang \& McBride, 2016; Wei, Bi, Chen, Liu, Weng, \& Wydell, 2014), but also lays the foundation for the orthographic knowledge in OPC rules (Ho et al., 2003).

About $90 \%$ of Chinese characters are ideophonetic compounds, which consists of two functional components: (a) a semantic radical, providing categorical meaning (Shu \& Anderson, 1997), and (b) a phonetic component, cueing phonological 
information of the ideophonetic compounds (Shu et al., 2000). The functional components can be (1) simple independent characters (e.g., $\square /$ kou3/, a semantic radical or 立/li4/, a phonetic component); (2) a stroke pattern (e.g., 小 a semantic radical of "heart", which does not have a corresponding pronunciation and is referred to as 豎心旁/shu4-shin1-pang2/; 它 a phonetic component, which can only be pronounced while being attached to a semantic radical), or (3) a combination of several stroke patterns (e.g., 言/ian2/, a semantic radical or 青/ching1/, a phonetic component). The phonetic component in an ideophonetic compound may provide full phonological information (e.g., the phonetic component 青/ching1/provides completely regular phonological information to its ideophonetic compounds 清 /ching1/ or 蜻/ching1/). However, around $60 \%$ of these phonetic components of the ideophonetic compounds are irregular, and only cue phonological information partially in syllables (e.g., 青/ching1/ of 請/ching3/ at the first and third tone, respectively), or onset (e.g., 青/ching1/ of 倩/chian4/), or rime (e.g., 青/ching1/ of 菁/jing1/), or complete exceptions (e.g., 青/ching1/ of 猜/tsai1/).

The pronunciation of an ideophonetic compound can also be deduced from other ideophonetic compounds sharing the same phonetic components (i.e., phonetic neighbors) by analogy. For instance, the ideophonetic compounds 忱/chen2/ has an unpronounceable bound phonetic component 光, but the pronunciation of 忱 is similar to other known phonetic neighbors, such as 沈/shen3/ or 枕/zhen3/ by analogy. Such analogy is a case of consistency, where ideophonetic compounds share the same phonetic component regardless whether the phonetic component's pronunciation is the same or different from that of the character (Fang, Horng, \& Tzeng, 1986). According to Fang et al. (1986), three characters 菁, 精 and 睛 are pronounced identically as /jing 1/ out of a consistency group of ten phonetic neighbors (i.e., 青/ching1/, 蜻 /ching1/, 情/ching2/, 晴/ching2/, 請/ching3/, 菁/jing1/, 精/jing1/, 睛/jing1/, 倩 
/chian4/, and 猜/tsai1/). Their consistency value would be 0.3 (i.e., 3/10).

The regularity and consistency of Chinese characters have been speculated to affect the use of OPC rules when reading ideophonetic compounds by developing readers (Shu \& Wu, 2006) or skilled readers (Fang et al., 1986), as well as learners of Chinese language (Lin \& Collins, 2012). It has been demonstrated that children would become aware of phonetic regularity as early as grade 2, while the awareness of phonetic consistency would appear later in grade 4 (Shu \& Wu, 2006).

Chinese children of early grades start using OPC rules to read novel ideophonetic compounds as a strategy for acquiring more characters (Chen, 1993; Ho \& Bryant, 1997b; Ho et al., 2003; Shu et al., 2000). Ho and Bryant (1997b) investigated the development of adopting OPC rules when reading ideophonetic compounds that were regular, semi-regular (tone-different) or exceptions by grades 1 and 2 children. Their results suggested that reading performance was significantly better in regular ideophonetic compounds than semi-regular characters or exceptions. They also found that children made phonetic-related errors when over using regular OPC rules on irregular/inconsistent ideophonetic compounds. Those phonetic-related errors include (1) reading an ideophonetic compound (/擴/kwong3/) by its phonetic component (e.g., 廣/gwong2/) using derivation strategy; or (2) reading a character (e.g., 怕/pa3/) as its phonetic neighbor (e.g., 伯/baak9/) using analogy strategy. Their results illustrated that early graders over relied on OPC rules by derivation or analogy when reading novel characters, nevertheless the use of OPC rules was significantly related to Chinese word reading ability (Ho \& Bryant, 1997b).

Since Chinese characters have low regularity and consistency, Anderson et al. (2003) speculated that regular OPC rules could not cope with the knowledge required for reading Chinese characters and children need to be aware of the sophisticated OPC rules before becoming skillful readers. Being aware of the sophisticated OPC rules 
means (1) becoming aware of the pronunciation irregularity/inconsistency between ideophonetic compounds and their respective phonetic components or neighbors; (2) being capable of using partial phonological information when learning to read novel ideophonetic compounds (Anderson et al., 2003; Shu et al., 2000).

Shu et al. (2000) examined the development process of using regular or sophisticated OPC rules among primary school children in grades 2, 4 and 6 with three types of ideophonetic compounds: (1) regular characters (i.e., the phonetic component provides full information for the ideophonetic compound, e.g., 會/hui4/ for 繪/hui4/); (2) irregular characters (i.e., the pronunciation of the ideophonetic compound is partially different from its phonetic component, e.g., 各/ge4/ for 略 /lue4/) and (3) characters with an unpronounceable bound phonetic component (e.g., 忱). The results showed that participants in all grades performed better at reading regular characters than irregular ones or characters with a bound phonetic component. Phonetic-related errors analysis, as shown in Ho and Bryant's study (1997b), revealed that OPC rules by derivation or analogy were employed by all graders but error rates increased with grades. Therefore, it was suggested that these primary children relied on regular OPC rules which could not cope with more and more non-regular characters that they would learn.

Anderson et al. (2003) designed a learning task to examine Chinese $2^{\text {nd }}$ and $4^{\text {th }}$ graders' abilities at using regular vs. sophisticated OPC rules. Children were required to learn reading four types of ideophonetic compounds over two learning trials. Those four types of ideophonetic compounds are: (1) regular, (2) tone-different (i.e., the phonetic component provides syllabic information for the ideophonetic compound), (3) onset-different (i.e., the phonetic component provides rhyming information for the ideophonetic compound), and (4) unknown-phonetic ideophonetic compounds (i.e., the phonetic component provides little information for the ideophonetic compound). 
Their phonetic components of regular, tone-different, and onset-different ideophonetic compounds were familiar characters chosen from textbooks of the lower grades, but the unknown-phonetic ideophonetic compounds were of unfamiliar characters, which were not taught explicitly in the textbooks of grade 1 through grade 4 . In their study, the researcher randomly read the four types of ideophonetic compounds (i.e., the test characters) one by one to the participants who were asked to write down the pronunciation by pinyin on their test sheets. They found that the accuracy of applying regular OPC rules to reading regular ideophonetic compounds was substantially higher than that by using sophisticated OPC rules on reading irregular ones (i.e., toneor onset-different ideophonetic compounds). Their finding is in good agreement with previous studies by Ho \& Bryant (1997b) or Shu et al. (2000) that second graders were already aware of the function of phonetic components. They further revealed that children had better performances on learning the pronunciation of tone- or onsetdifferent characters than on phonetic unknown characters, suggesting that those children of grade 2 already started using partial phonological information to learn to read novel characters (i.e., by sophisticated OPC rules).

Since non-ideophonetic compounds do not have phonetic components, they could only be read by direct mapping characters to their respective pronunciations. The mapping skill has been examined through various paired associate learning (PAL) tasks, including visual-visual (e.g., associating a visual symbol with an animal picture), visual-pronunciation (e.g., associating an animal picture with a nonsense syllable), and visual-semantic (e.g., associating a visual symbol with a meaningful object) associations (Chow, 2014; Li et al., 2009). Chow (2014) suggested that PAL skill in the visual-semantic modality would predict Chinese word reading for second graders. Li et al. (2009) demonstrated that dyslexic children of fifth and sixth grades had significantly poorer performance in visual-pronunciation modality than non- 
dyslexic children, but there was no significant difference in the visual-visual modality between the two groups. These results suggested that mapping skills in visualsemantic and visual pronunciation are two distinct but important PAL skills during the reading development. Therefore, our study employed PAL skills in characterpronunciation (i.e., visual-pronunciation modality) as a controlled reference for the reading performances through OPC rules.

Taken together, the configuration and structure knowledge are acquired during the rudimentary stage of orthographic development. The more advanced orthographic skills for character reading may be dependent upon the ability to use OPC rules, which can be further categorized into (1) regular OPC rules by retrieving phonological information from the phonetic components/neighbors, or (2) sophisticated OPC rules by taking cues from the partial phonological information embedded in Chinese characters. Therefore, our study investigated the developmental relationship between those abovementioned orthographic knowledge to character reading, but using direct mapping as a control.

\section{Phonological awareness and Chinese character reading development}

The importance of phonological awareness in reading Chinese characters has been demonstrated longitudinally (Ho \& Bryant, 1997a; Huang \& Hanley, 1997; McBride-Chang \& Zhong, 2003) and cross-sectionally (Chan \& Siegel, 2001; Ho \& Bryant, 1997b; Hu \& Catts, 1998; Huang \& Hanley, 1994; Siok \& Fletcher, 2001; Shu, Peng, \& McBride-Chang, 2008; Wei et al., 2014) across pre-school and early primary school years. Each Chinese character corresponds to one Chinese syllable, and early readers tend to map Chinese characters onto their pronunciations at the syllable level. Therefore, syllable deletion was shown to be the most salient variable in character reading for preschoolers (McBride-Chang \& Ho, 2005; McBride-Chang \& Zhoung, 
2003; Shu et al., 2008).

Many studies have demonstrated that tone awareness is associated with character recognition for preschoolers (Ho \& Bryant, 1997a; McBride-Chang et al., 2008; Shu et al., 2008) as well as early graders (Li \& Ho, 2011; Siok \& Fletcher, 2001). Ho and Bryant (1997a) used a rime-tone detection task to assess children's ability at identifying the sound from two choices (e.g., /toi2/ or /maau1/) that rimes with (/hoi2/) and have the same tone. The correct answer is /toi2/ in this case. Their results suggested that the awareness of tone with rime at the age of 4 was longitudinally related to character reading by the age of 7 . Tone awareness was assessed by syllables in later studies (Li \& Ho, 2011; Siok \& Fletcher, 2001), in which children were asked to name the odd syllable with a different tone among several choices (e.g., /hie1/, /feng1/, /tao1/, /shui3/ where /shui3/is the odd one out). Siok and Fletcher (2001) found that tone awareness was marginally related to character reading in grade 2 , but not in grade 1. Li and Ho's (2011) study further suggested that grade 2 dyslexic children revealed a developmental delay in processing tone differences. To date, the investigation specific to the development of tone awareness and character reading from grade 1 to 2 is still scant.

In Taiwan, formal character recognition is introduced after a 10-week instruction of Tzuyin system. Huang and Hanley (1997) examined character reading and the development of phonological awareness at sub-syllabic level among Taiwanese grade 1 children longitudinally. They tested children's phonological awareness and character reading in three critical time points: (1) the beginning of Tzuyin instruction in grade 1(session 1); (2) right after Tzuyin instruction (session 2) and (3) the end of grade 1(session 3). Their results showed that Tzuyin instruction improved children's onset and rime awareness considerably in session 2 . The improvement in onset and rime awareness from session 2 to 3 was still significant but less so when compared to that 
from session 1 to 2 . In contrast to phonological development, their development in character reading from session 2 to 3 was more significant than from session 1 to 2 . Although phonological awareness in session 1 uniquely explained character reading in session 3, the weight that early phonological awareness accounted for later character reading turned out to be very limited after the initial reading scores were factored into the regression equation. They suggested that early character reading itself but not phonological awareness underpins children's later character reading for grade 1 children. However, some other important skills in phonological awareness such as syllable (McBride-Chang \& Ho, 2005; McBride-Chang \& Zhoung, 2003; Shu et al., 2003) or tone (Li \& Ho, 2011; Siok \& Fletcher, 2001) were not included in Huang and Hanley's (1997) study. This may explain why phonological awareness was not able to predict character reading uniquely for grade 1 children.

In brief, the role of phonological skills in character reading may shift along the developmental line. Syllable awareness is critical to character reading for initial readers (McBride-Chang \& Ho, 2005), while onset, rime or tone awareness are more important in the successive years of learning to read (Hunag \& Hanley, 1997; Li \& Ho, 2011; Siok \& Fletcher, 2001). Therefore, the question arises as to which phonological skill plays a major role in character reading from grade 1 to grade 2 .

\section{Phonological awareness and using OPC rules to read}

Because the phonetic component in Chinese characters provides phonological information, phonological awareness is assumed to be particularly important when using OPC rules to read. Ho and Bryant's (1997b) study suggested that phonological awareness was important when using OPC rules by $1^{\text {st }}$ graders only. But the significance diminished when the ability of using regular OPC rules was taken into account. Ho and Bryant (1997b), therefore, speculated that the phonological 
awareness in the sophisticated OPC rules is based on the awareness of regular OPC rules. Interestingly, Anderson et al. (2003) postulated that phonological awareness is particularly important in the sophisticated OPC rules at the sub-syllabic processes when retrieving partial phonological information with syllable, onset, or rime elements. He et al. (2005) used the same experimental procedures of Anderson et al.'s (2003) study but came to suggest that phonological awareness was important for learning to read identical, or tone-different, or onset-different, or even unknownphonetic ideophonetic compounds, indicating that phonological awareness is universally important in character reading regardless the use of regular or sophisticated OPC rules.

However, there were some doubts in the research design which might lead to bias conclusions by Anderson et al. (2003) or He et al.'s (2005) studies. First, while the participants may not be able to read all of those familiar phonetic components of identical or partially different ideophonetic compounds; they could guess read those unfamiliar phonetic components. Second, although students at low, middle, or high reading levels were purposely chosen according to their reading ability, the participants in these studies were recruited from Beijing, Guangzhou or Dalian, where most students from these major cities may have been exposed to those unfamiliar ideophonetic compounds even though these characters had not been taught explicitly at school.

Ho, Wong, and Chan (1999) used a cluing paradigm to examine whether children could be prompted by a clue character (e.g., 爐/lu2/) to learn to read a new ideophonetic compound (e.g., 鱸/lu2/) sharing a regular phonetic component (i.e., 盧 /lu2/) by analogy. They trained children to master the clue characters first so that children had equal knowledge about the clue characters, and then the students were asked to read the test characters (i.e., the unknown ideophonetic compounds), which 
gave a baseline of reading performance in a pre-test session. The participants were then required to read the test characters with the clue characters in sight during the post-test. In contrast to the conclusion made by He et al. (2005) or Ho and Bryant (1997b), their results indicated that phonological awareness was not associated with reading improvement. Therefore, we speculate that the relationship between phonological awareness and the use of OPC rules in previous studies (He et al., 2005; Ho \& Bryant, 1997b) may be explained by children's prior knowledge in the clue or test characters. Consequently, two additional factors need to be considered in future research designs: (1) children's familiarity with the phonetic components/phonetic neighbors as well as a baseline for the test characters need to be established and (2) the association of phonological awareness to character reading without using OPC rules (mapping strategy).

\section{The present study}

The present study aimed to clarify the role of phonological and orthographic awareness in learning to read Chinese characters from grade 1 to 2 . We examined the development of phonological awareness (onset, rime and tone awareness), orthographic knowledge (rudimentary and OPC rules) and character reading from grade 1 to 2 among 112 Taiwanese students. Participants' pure visual skill, verbal IQ and non-verbal IQ were assessed as control variables.

Since grade 2 has been shown to be a transitional period for children to refine their knowledge in OPC rules from over using regular OPC rules to sophisticated OPC rules, a learning task was designed to simulate such a scenario that those second graders may face. In the learning task, participants were elicited to learn to read novel characters through three orthographic to phonological strategies. The first two required either regular or sophisticated OPC rules, and the third used no OPC rules 
(mapping strategy). Corresponding phonetic components or bound ideophonetic compounds of the test characters were used as the clue characters to elicit the application of either regular or sophisticated rules; while the test characters by direct mapping had no corresponding phonetic components. The clue characters, familiar characters selected from the text books for first and second graders, were included to see how well children connect them to the rest of test characters through either regular or sophisticated OPC rules. The baseline performance was measured prior to the learning task which is consisted of a practice session of clue characters and an instruction session of test characters. Children's baseline performance was used for assessing the initial knowledge of those test characters. The practice session was to ensure that children's clue character knowledge for regular or sophisticated OPC rules were at the same level.

Two developmental questions were investigated on grade 1 students in transition to grade 2: (1) does phonological/orthographic awareness affect character reading concurrently and longitudinally from grade 1 to grade 2 ? Specifically, which linguistic skills are the unique predictors for character reading? (2) How effective are these reading strategies (regular vs. sophisticated OPC) when reading novel characters, and whether reading strategies are correlated to character reading and linguistic skills from grade 1 to 2 ?

Method

\section{Participants}

One hundred and twenty Chinese-speaking first graders (mean age $=7$ years 2 months; $S D=3.1$ months) were recruited from four primary schools in Taipei with informed consent. All four schools used a common reading textbook with a similar pedagogical approach, namely, a teacher-centered lecture and a phonological 
approach to reading instruction based on Tzuyin system. According to the teachers' reports, these students were typical children with no need of special education. During grade 2, eight students dropped out $(6.9 \%)$ for various reasons. One student was quarantined due to disease infection; five were transferred to other schools; two students' parents withdrew from the test. The remaining 112 students went on participating in the study in grade 2 (mean age $=8$ years 2 months, $S D=2.9$ months).

\section{Materials and Procedures}

The participants' abilities in character reading, phonological awareness, orthographic awareness, visual matching, and verbal IQ were assessed during the second semesters of grade 1 and 2. Non-verbal IQ was assessed in grade 1. After the grade 2 tests, the participants were asked to perform an experimental learning task designed for this study.

Character reading. The Chinese Graded Character Reading Test that had been used in Huang and Hanley's (1994, 1997) study and standardized in Taiwan (Huang, 2001), was administered to assess children's character reading ability. This test consists of 200 single Chinese characters arranged with an ascending difficulty which had an internal consistency reliability of $.99(p<.001)$. The participants were asked to read each character aloud in Mandarin. One point was given for each correct response and the test was ceased if a participant failed to read 20 characters consecutively.

Phonological awareness. The phonological test assessed participants' onset, rime, and tone awareness. Participants were tested individually in a quiet classroom. Onset, rime, and tone awareness tests were administered in randomized order. In the onset and rime tests, children were asked to choose the odd syllable out of four spoken Chinese syllables that were different in sound segments of onset or rime. For example, children were required to choose /pao/ out of /ba/, /bo/, /bei/, and /pao/, because the 
onset /p/of /pao/ is different from the other three; and choose /bian/ out of /jia/, /qia/, /bian/, and /shia/, because /ian/ of /bian/ is the odd final vowel among the four items. In the tone test, children listened to three different tones attached to an identical syllable (e.g., /so4/, /so3/ and /so1/) first. After a 1-second interval, they listened to two of the three tones again (e.g., /so4/ and /so1/), and then were asked to say the missing tone (i.e., /so3/).

The onset, rime and tone awareness tests each consisted of four practice trials and 20 test items. These sets of phonological tests were piloted on 32 first graders. The test-retest reliability for onset, rime, and tone awareness were $.80, .79$, and .72, respectively.

Rudimentary orthographic knowledge. Children's rudimentary orthographic knowledge in character constituents and structure was assessed using two sub-tests (Configuration Matching Test and Structure Knowledge Test) from Test of Visual Perception of Chinese Characters (Hung, 2001).

Configuration Matching Test was consisted of 20 items, which were designed to assess children's sensitivity to the graphic units of Chinese characters. Each item consisted of one target (e.g., 榦) followed by four randomly arranged alternatives, including: (1) completely identical graphic units (幹); (2) different graphic unit in form constraint (e.g., 朝, in which square $\square$ is replaced by an circular O, which is not a Chinese graphic unit); (3) different graphic unit in strokes (e.g., 䨐, in which 曰 is replaced by $⿴$ in the left half of target pseudocharacter) and (4) flipped positions (e.g., 会). The children were asked to identify the target out of those alternatives, and to write their choice on their answer sheets (the correct answer in this case is 1).

Structure Knowledge Test used the lexical decision paradigm, which included a set of 24 pseudo-character and non-character pairs with two additional pairs for 
practice, as adopted from Hung's (1997) study. Children were asked to circle the character in each pair that they judged as more like a Chinese character according to the rules of orthographic structure. For example, within the character pair of “女井” and “反片”, “女井” is the correct answer, because the radical 女 only appears on the left side of a character; while the stroke pattern 片 never appears on the right side of a character. Participants were tested in groups with a limit of 3 minutes on configuration matching and 6 minutes for structure knowledge. One point was given for each correct answer. The internal consistency reliability for tests of configuration matching and structure knowledge were .91 and .79 , respectively.

Visual Matching. Figure Matching Test adopted from Hung (2001) is a nonorthographic equivalent of Configuration Matching Task using non-semantic symbols. The purpose of the task is to isolate and assess pure visual skills. Each item is consisted of one target non-semantic symbol followed by four different alternatives (e.g. (ㅁ) followed by (1) ) children were asked to identify the exact match and write down their choice on their answer sheets (the correct answer here is 2). The test is consisted of 2 practice and 18 test items. Participants were tested in groups with a limit of 3 minutes. One point was given for each correct answer. The internal consistency reliability for the test was .53 .

Verbal IQ. The Chinese version PPVT (Lu \& Liu, 1988) was utilized to measure the participants' receptive oral vocabulary knowledge. This test was developed based on the Peabody Picture Vocabulary Test- Revised (Dunn \& Dunn, 1981) with internal consistencies from .90 to .97 . The test was consisted of 5 practice items followed by 125 test items. In each test item, a vocabulary was presented orally in Mandarin, and then the participant was asked to point to a picture corresponding to the meaning of the vocabulary among four alternatives put together in one page.

Non-verbal IQ. Raven's Colored Progressive Matrices (RCPM) was used to 
measure non-verbal IQ. The test was standardized in Taiwan by Yu (1993) with a testretest reliability of .90 for children between 4 to 8 years old. Participants were required to select one answer that best fits the missing part of the target matrix from six to eight alternatives. The test incorporated three sets of tasks with 12 items in each set and was administered by groups with a 30 minutes session. One point was awarded for each correct response.

Learning Task. The learning task was designed to assess children's ability to learn to read novel characters through different orthographic to phonological strategies. It was consisted of 30 test characters and 20 clue characters while ten test characters had no corresponding clue characters (see Appendices). The test characters were made up by three character types to which phonological information was provided from the clue characters at three different levels: (a) ideophonetic compounds with identical pronunciation from their clue characters (i.e., regular OPC rules); (b) ideophonetic compounds with partially different pronunciation (tone or onset) from their clue characters (i.e., strategy by the sophisticated OPC rules) and (c) non-ideophonetic characters without any phonetic component or corresponding clue character (i.e., mapping strategy). Ten of the 20 clue characters that functioned to cue regular or sophisticated OPC rules ( 5 characters each) were the phonetic components of the test character; the other 10 were ideophonetic compounds sharing the same bound phonetics as the test characters.

All those 30 test characters were chosen from the Mandarin Chinese Character Frequency List (Chinese Knowledge Conformation Processing Group [CKCPG], 1995), and were unfamiliar characters with a relatively low frequency of exposure. The difficulty (i.e., frequency of exposure) and visual complexity (i.e., stroke counts) of the test characters were equalized among these three types. The average frequencies (out of 5,666 Chinese characters) and their standard deviations, in 
parentheses, of those characters in regular OPC rules, sophisticated OPC rules, and mapping strategy were $11.90(4.01), 14.00$ (4.67), and 13.50 (1.84), respectively. The average stroke counts and their standard deviations, in parentheses, of the three types of test characters were $14.70(3.40), 13.30(3.40)$, and 13.70 (1.83), respectively. The consistency values of the test characters were also calculated based on the most frequent 1,000 characters in the Mandarin Chinese Character Frequency List. The average consistencies and their standard deviations, in parentheses, of regular and sophisticated OPC rules were $0.96(0.14)$ and $0.73(0.29)$, with no significant difference between them, $t(9)=1.70, p=0.12$.

Each child undertook the learning task individually in a quiet classroom. The researcher led the child through four successive sessions, which were (1) the baseline session of the test characters; (2) the practice session of the clue characters; (3) the instruction session of the test characters and (4) the re-test session. Baseline, instruction, and re-test sheets had the same 30 test characters, but they were placed randomly in a 5 by 6 format. The practice sheet had 20 clue characters, which were printed in 48 point font size (Microsoft word).

In the baseline session, each participant was asked to read aloud the 30 test characters without instruction. This gave a measure of the initial baseline performance. In the practice session of clue characters, children were first asked to read all the clue characters on the practice sheet. Most participants made a couple mistakes initially when reading the clue characters. The researcher then demonstrated the pronunciation of any clue character the child had missed out, and asked the child to follow the researcher's lead for several repetitions. The child was not introduced to the test characters until he or she was able to read all of the clue characters correctly three successive times. This session typically took 1 to 10 minutes depending on the proficiency of the participants. In the instruction session of test characters, the child 
was asked to follow the researcher's lead and read aloud the test characters one by one. The same demonstrating procedure was repeated three times. The instruction session lasted approximately 10 minutes for each child. The phonological function of the clue characters in relation to the test characters was not taught. After the instruction session, the child was asked to read aloud each test character on the re-test sheet by himself or herself in the re-test session as to assess his/her learning outcome. One point was given for each character read correctly. The total score of each character type was 10 and the Cronbach's $\alpha$ was .71. The split-half reliability of the three character types were $.74, .70$, and .79 , respectively.

\section{Statistics}

Prior to the statistical analyses, variables of character reading, phonological awareness (onset, rime, and tone), rudimentary orthographic awareness (configuration matching and structure knowledge), visual matching, verbal and non-verbal IQ as well as the baseline and re-test scores of the three strategies were examined through various SPSS programs for accuracy of data entry, missing values, and fit between their distributions. Two students were found to have extremely high $z$ scores on character reading in grades 1 and 2 . Their parents had taught their children to recognize Chinese characters before age 3 or 4 , and they were not actually using Tzuyin as an auxiliary tool to read. Two other cases were identified through Mahalanobis distance as multivariate outliers with $p<.001$. All four outliers were deleted leaving 108 cases for analyses (mean age $=8$ years 2 months, $S D=3.0$ months). 


\section{Results}

The relationship between phonological, rudimentary orthographic awareness and character reading from grade 1 to 2

The means, standard deviations and percentage scores on all the tasks administered in grades 1 and 2, together with results from paired $t$-tests comparing performances from grade 1 to 2 were given in Table 1 . The children's phonological and orthographic awareness scores were above chance level, indicating that they did not respond to the tests randomly. The $t$-test results suggested performances in character reading, phonological awareness (rime and tone), rudimentary orthographic knowledge (configuration matching and structure knowledge), and control variables of visual matching and verbal IQ improved significantly from grade 1 to 2 . Onset awareness, however, did not improve significantly $(p=.71)$. Scores in visual matching test appeared to show the ceiling effect in both grades, which would explain the lower reliability $(.53)$ of this test.

\section{[insert Table 1 here]}

Table 2 showed the correlation matrix of the scores on all the tests taken at grades 1 and 2 . Grade 1 character reading was moderately associated with all the reading related variables in phonological $(r s=.31 \sim .43)$ and rudimentary orthographic awareness ( $r \mathrm{~s}=.24$ and .33 ), and a similar pattern of correlation was observed between the reading related variables and character reading at grade 2 (phonological awareness: $r \mathrm{~s}=.31 \sim .44$; rudimentary orthographic awareness: $r \mathrm{~s}=.27$ and .33).

Longitudinally, grade 1 character reading was highly correlated to that in grade 2 
$(r=.71, p<.001)$. All reading related variables in grade 1 were found to be significantly related to grade 2 character reading $(r s=.25 \sim .49)$. Verbal and nonverbal IQ were also significantly correlated to character reading in both grades ( $r \mathrm{~s}$ $=.31 \sim .40$ ). The correlations of phonological awareness (onset, rime, and tone) and verbal IQ at grade 1 with those of grade 2 were strong $(r s=.65, .72, .59$, and .65 , respectively), while visual matching, configuration matching, and structure knowledge in grade 1 were moderately correlated to that in grade $2(r \mathrm{~s}=.27, .39$, and .35 , respectively).

[insert Table 2 here]

The hierarchical multiple regression was employed to determine to what degree character reading was influenced by phonological or rudimentary orthographic awareness, when IQ and visual skill were controlled. In the first regression model (Table 3a), grade 1 character reading was the dependent variable, non-verbal IQ, verbal IQ, and visual matching served as control variables in the first step. The predictor variables of rudimentary orthographic awareness or phonological awareness were entered in the second step. In the second regression model (Table 3b), grade 2 character reading served as the dependent variable, and the order of control variables and predictor variables at grade 2 were entered the same as the first model. The third regression model (Table 3c) examined the variance of grade 2 character reading explained by grade 1 phonological or rudimentary orthographic awarenesses longitudinally. Grade 1 verbal, non-verbal IQ, and visual matching served as control variables and were entered in the first step, followed by grade 1 character reading, and the final two steps were either phonological awareness first or orthographic awareness first. 
[insert Table 3a here]

[insert Table $3 \mathrm{~b}$ here]

[insert Table $3 \mathrm{c}$ here]

As shown in Tables $3 \mathrm{a}$ and $3 \mathrm{~b}$, the analyses of the concurrent predictors of character reading revealed that rudimentary orthographic knowledge and phonological awareness both contributed unique variance to character reading in grade $1\left(\Delta R^{2}\right.$ $=.050, p=.044$ and $\Delta R^{2}=.105, p=.004$, respectively $)$ and grade $2\left(\Delta R^{2}=.045, p\right.$ $=.056$ and $\Delta R^{2}=.078, p=.018$, respectively), after controlling for verbal, non-verbal IQ, and visual matching. The final beta weights showed that the significant predictors for character reading were structure knowledge and rime awareness in grade 1 (Table $3 a)$; but none of the predictors was significant in grade 2 (Table $3 b$ ).

The third model (Table 3c) showed the longitudinal dependency of grade 2 character reading on grade 1 skills. Grade 1 predictors and character reading together accounted for $59.2 \%$ of the variance in grade 2 character reading, $F(9,98)=15.83, p$ $<.001$. As expected, grade 1 character reading contributed a major part of variance $(35.1 \%)$ in grade 2 character reading $\left(\Delta R^{2}=.351, p<.001\right)$. Phonological awareness contributed a smaller but still significant part of variance $\left(\Delta R^{2}=.040, p=.03\right)$ in grade 2 character reading. The final beta weights of the variables showed that tone awareness was the only significant predictor of grade 2 character $(t=2.06, p=.04)$, which uniquely explained $1.8 \%$ of variance for grade 2 character reading.

\section{Learning Performances in using different orthographic to phonological strategies}

The data from children's performances on the learning task (Table 4) were subjected to repeated measures of ANOVA with three strategies (regular or 
sophisticated OPC rules, and the mapping strategy) and 2 test time-points (the baseline and the re-test scores) as within-subjects factors. The results revealed that there were significant main effects of Strategy, $F(1,157)=747.98, p<.001, \eta_{\mathrm{p}}^{2}$ $=.875$, and Time, $F(1,107)=241.62, p<.001, \eta_{\mathrm{p}}{ }^{2}=.693$. Bonferroni contrasts showed that the performance using regular OPC rules was significantly better than using sophisticated OPC rules (mean difference $=5.03, p<.001$ ) or the mapping strategy (mean difference $=4.68, p<.001$ ). The improvement from the baseline to retest was also significant (mean difference $=1.72, p<.001$ ). The interaction between Strategy and Time was also significant, $F(2,161)=45.00, p<.001, \eta p^{2}=.296$.

The results suggested that the improvement in learning to read novel characters by three different strategies was also significantly different. Planned contrasts were used to analyze improvement in each strategy from baseline to re-test separately. Improvement in learning to read test characters by using regular OPC rules was significantly greater than using sophisticated OPC rules, $t(107)=8.12, p<.001$, or mapping strategy, $t(107)=6.09, p<.001$. Interestingly, the mapping strategy was somehow better than the sophisticated OPC rules, $t(107)=3.07, p=.003$.

[Insert Table 4 here]

The relationship between character reading, phonological awareness, rudimentary orthographic knowledge, and learning performances in using varied orthographic to phonological strategies

Table 5 showed the partial correlations between three different learning strategies and character reading, phonological and rudimentary orthographic awarenesses at grades 1 and 2, after controlling for verbal, non-verbal IQ and baseline knowledge of test characters. Grade 1 and grade 2 character reading were significantly correlated to 
learning performances by using sophisticated OPC rules or mapping strategy $(r s=.40$ $\sim .49, p \mathrm{~s}<.001$ ), but not with regular OPC rules ( $r$ s $=.05$ and .06 , respectively, $p \mathrm{~s}$ $>.50)$.

Correlations between learning strategies and sub-skills of phonological or rudimentary orthographic awarenesses were different. Phonological awareness (i.e., rime in both grades and grade 1 tone, $r \mathrm{~s}=.33, .31$, and .29 , respectively) and rudimentary orthographic awareness (i.e., configuration matching in grade 2 and structure knowledge in both grades, $r \mathrm{~s}=.20, .24$, and .22 , respectively) were correlated to learning performance using sophisticated OPC rules. The correlation between grade 1 structure knowledge and regular OPC rules were also significant ( $r$ $=.24, p=.02)$. Correlations between phonological/rudimentary orthographic awarenesses and performances by regular OPC rules or mapping were relatively low.

\section{Discussion}

This study investigates the influence of phonological and orthographic awareness on character reading from grade 1 to 2 . Two important findings are reported. First, grade 1 phonological awareness predicts character reading in grades 1 and 2 while rudimentary orthographic knowledge only predicts character reading in grade 1 . Longitudinally, phonological awareness predicts grade 2 character reading after verbal, non-verbal IQ, visual matching, rudimentary orthographic knowledge and grade 1 character reading are adjusted. Among the sub-skills of phonological awareness, (1) rime awareness predicts character reading in grade 1 but not in grade 2 and (2) grade 1 tone awareness predicts grade 2 character reading. Second, the learning performance through regular OPC rules is apparently more effective than sophisticated OPC rules or mapping strategy, but surprisingly, the sophisticated OPC rules and mapping 
strategy are more influential to character reading in both grade 1 and 2 . In addition, phonological awareness in rime/tone and rudimentary orthographic knowledge are significantly associated with learning novel characters only when using the sophisticated OPC rules.

The prediction of phonological awareness for character reading during grade 1 and grade 2

Our finding reinforces Huang and Hanley's (1997) conclusion that phonological awareness is important for grade 1 children. This study adds to Huang and Hanley's (1997) findings by combining variances in onset, rime and tone of phonological awareness that helps to explain a significant amount of variance in character reading in grade 1. For longitudinal investigation, Huang and Hanley (1997) suggested that phonological awareness in early grade 1 predicted character reading 8 months later. Our study expands their theory and suggests that phonological awareness at the end of grade 1 also predicts character reading in grade 2.

The obligatory characters to learn in the first three grades range from 1000 to 1200 characters, according to the nine-year-consistent curriculum in Taiwan (Ministry of Education, 2001). It has been estimated that Taiwanese first, second and third graders were taught with 712, 1249 and 2108 characters, respectively (Wang, Hung, Chang, \& Chen, 2008), suggesting that grade 1 to 2 is a crucial period for Taiwanese children to accumulate a sufficient number of characters to read. During this period, Tzuyin becomes a particularly important tool assisting children's ability to acquire more new characters. Because Tzuyin is a system of representing the pronunciation of unknown characters in onset, rime and tone, the influential role of combined phonological skills in character reading from grade 1 to 2 may be due to the high reliance on Tzuyin system. 
Our study also indicates that tone awareness in grade 1 predict grade 2 character reading longitudinally, when other related skills and the autoregressor of grade 1 character reading are controlled strictly. This result confirms previous research findings (Li \& Ho, 2011; Siok \& Fletcher, 2001) and suggests that tone awareness is an important linguistic skill in the initial years of learning to read. A previous study (Ho \& Bryant, 1997a) suggested that rime awareness assessed with tone at the age of 4 longitudinally predicted character reading at 7 years old (grade 1). Our study expands their conclusion and suggests that rime awareness, assessed independently of tone, uniquely predicts character reading in grade 1 but not grade 2 . Rime is the segmental unit within a syllable, so the reason why rime awareness is significantly related to grade 1 character reading might be due to the fact that first graders know fewer characters so that they read new words by Tzuyin sub-syllabically more often than second graders. The second graders know more characters than first graders, which might divert their heavy reliance from using Tzuyin to other reading strategies (e.g., OPC rules).

Our results differ partially from those of Siok and Fletcher (2001) who suggested that phonological awareness was only related to character reading significantly among grade 2 children. In Siok and Fletcher's (2001) study, the first graders' character reading ability was assessed with characters that have been taught, that is, very familiar characters. Under such a condition, children may retrieve their known characters easily as a whole. While the second graders' character reading was assessed with characters of more advanced level, which entailed more complex reading related skills. Therefore, the importance of phonological awareness in Siok and Fletcher's (2001) study might have been underestimated in grade 1 . 
Orthographic awareness and Chinese reading development

Our study finds that rudimentary orthographic knowledge predicts character reading in grade 1 , but not in grade 2 . The results are in line with previous studies (McBride-Chang \& Ho, 2005; Pak et al., 2005; Siok \& Fletcher, 2001; Wang \& McBride, 2016; Wei et al., 2014), suggesting that some rudimentary orthographic knowledge, including configuration and structure of Chinese character, plays an important role in the very early stages of learning to read. Our explanation to this limited predictability for the $2^{\text {nd }}$ graders is that there might be a ceiling effect associated with rudimentary orthographic knowledge, and, therefore, renders these tests less effective.

Our study finds that children's learning performance using regular OPC rules in grade 2 is apparently more effective than the sophisticated OPC rules or mapping strategy, which is in agreement with previous research (Anderson et al., 2003; Ho \& Bryant, 1997b; Shu et al., 2000). The Strategy effect in our results suggests that Taiwanese children have acquired the ability to use regular OPC rules to learn to read novel characters at no later than grade 2, despite that orthographic knowledge is not explicitly taught until grade 3 .

Interestingly, participants benefited more by using regular OPC rules than the other two learning strategies at reading novel characters, but their novel character reading performance using regular OPC rules was not correlated with their character reading. Our result agrees with Ho et al.'s (1999) findings but is different from those conclusions made by He et al. (2005) and Ho and Bryant (1997b). The discrepancy may be due to different experimental designs. In Ho et al.'s (1999) study and ours, participants were trained to pronounce all the clue characters prior to administration of their learning task. If accurate reading of all the clue characters is ensured, then knowledge of the clue characters is not related to reading ability per se. Since He et al. 
(2005) and Ho and Bryant (1997b) chose familiar phonetic components from text books in lower grades to cue the pronunciation of the test characters, children's knowledge in familiar components may, to some extent, contribute to the closer relationship between the use of regular OPC rules and character reading.

The present study suggests that using sophisticated OPC rules is associated with better reading ability. The results are in accordance with Anderson et al.'s (2003) finding that knowledge of sophisticated OPC rules instead of regular OPC rules is essential for being a more skilled reader. In Taiwan, children learn to read novel characters by using Tzuyin. During the first two grades, they were taught to read any novel characters by using Tzuyin system. Through this process, they may have more chances to find out the pronunciations irregularity between the phonetic components (or phonetic neighbors) and the ideophonetic compounds. This implies that more skilled readers with better phonological awareness may detect the irregularity of ideophonetic compounds through the processes of using Tzuyin to read during their early grades.

However, this does not mean that using regular OPC rules is not relevant to Chinese reading. Ho and Bryant (1997b) suggested that first and second graders in Hong Kong relied on regular OPC rules heavily to read novel characters. The reading development of children in Hong Kong is based on having learned hundreds of known characters from the logographic stage before grade 1 in order to understand and use OPC rules. Chinese readers are likely to use regular OPC rules intuitively whenever encountering characters with very low frequency. When they find the pronunciation of a novel character different from its phonetic component or other phonetic neighbors, more skilled readers will resort to sophisticated OPC rules by using partial phonological information to read. Therefore, the regular OPC rules is a default reading strategy, but an adoption of sophisticated OPC rules will make a better reader. 
Although using sophisticated OPC rules has been demonstrated to be a crucial skill for learning to read, the learning effectiveness was relatively weak when compared to mapping strategy. The explanation for this discrepancy is because of the partial conservation of pronunciation associated with sophisticated OPC rules that may mislead students to an incorrect pronunciation. This confusion may occur during the learning task, in which clue characters were practiced prior to the teaching of test characters. Under this condition, children were more likely to notice and place an emphasis on the clue characters, leading to a poorer performance in learning to read by sophisticated OPC rules. Therefore, future studies should arrange the sessions of "practice clue characters" and "teaching and re-test test characters" on different days to avoid such confusion. In addition, more trials during the instruction of the test characters might be helpful for learning outcomes.

Based on our study, we would suggest taking ideophonetic compounds into consideration when children are taught to read novel characters. It would be more efficient to learn a novel ideophonetic compound with its regular phonetic component or its consistent phonetic neighbor (i.e., through regular OPC rules). However, words with auditory or visual similarity should be introduced in separate lessons as suggested by Carnene, Silbert and Kameenui (1997). Accordingly, for efficient learning of reading irregular ideophonetic compounds, the novel ideophonetic compounds and the corresponding clue characters should be arranged in separate lessons as explained below. First, students need to master the clue characters, so that they can have a sense to detect and retrieve the partial information embedded within the clue and test characters. Second, explicit instruction would be necessary to avoid the confusion from partial similarity. These instructions should include: (1) how new characters are related or analogous to their corresponding clue characters and (2) what partial phonological information can be used in the characters. Finally, repeated 
exposure of the new characters is important to build a firm memorization.

The mapping strategy in this study entailed the core reading mechanism of PAL. This study extended previous evidence by providing a longitudinal relationship between PAL mechanism and Chinese reading development from grade 1 to 2 . Chow (2014) adopted pure visual symbols as learning stimuli, and suggested the visualsemantic PAL as the only predictive PAL modality for reading meaningful twocharacter words. Based on real Chinese characters as the learning materials, our results suggested that the orthographic with phonological PAL was important in reading single characters.

The correlation pattern between linguistic skills and learning to read using different OPC rules

Our study suggested that sophisticated OPC rules is the only reading strategy that is correlated to phonological awareness after possible interfering factors were controlled. This finding clarified the controversial speculation on the influence of phonological awareness on character reading when using regular OPC (Ho \& Bryant, 1997b) and/or sophisticated OPC rules (Anderson et al., 2003; He et al., 2005). The reason is because using sophisticated OPC rules to read novel ideophonetic compounds requires the ability to tell the difference in rime or tone between the test character and its phonetic component or phonetic neighbor.

He et al. (2005) and Ho and Bryant (1997b) speculated that the significant association between phonological awareness of rime, tone and character reading by regular OPC rules may be due to children's prior knowledge of the phonetic components. Our study confirmed their theory by demonstrating when children's knowledge of phonetic components were experimentally controlled, the correlation between phonological awareness and reading by regular OPC rules became no longer significant. 
Our study also suggested that rudimentary orthographic knowledge is salient when using sophisticated OPC rules. This result may be due to the sub-lexical process of retrieving useful information from the phonetic component of the character. The use of sophisticated OPC rules depends on basic knowledge in orthographic structure and constituents. Ho and her colleagues (2003) proposed a theory that the development of orthographic knowledge in OPC rules is based on the rudimentary orthographic knowledge. Our study further extends their findings by an indication that rudimentary orthographic knowledge is longitudinally related to the use of sophisticated OPC rules.

Our study is in line with Chow's 2014 finding that mapping strategy is only related to character reading, but not to linguistic skills at the sub-syllabic level. Further, using mapping strategy to learn reading does not depend on sub-lexical processes of configuration matching or structure knowledge. Our results suggest that using mapping strategy to read is a salient skill for early graders to learn to read new characters through a syllabic or lexical process. However, there are other important sub-skills when reading by mapping strategy not examined in this study. These skills may be their familiarity with various Chinese graphic units that have been suggested as intelligible units in Chinese orthography (Chan, 1996; Chan \& Nunes, 1998; Huang, 2003) or semantic information embedded in the semantic radical (Ho et al., 2003; Pak et al., 2005; Wang, Yin, McBride, 2015).

\section{Conclusion}

This study unfolds the relationship between phonological/orthographic awareness and Chinese reading acquisition. First, composite phonological awareness in onset, rime and tone can predict character reading concurrently in grade 1 and 
longitudinally from grade 1 to 2 . Second, rudimentary orthographic knowledge explains a significant part of character reading in grade 1, while the sophisticated OPC rules and mapping strategy are important to character reading in grade 2 . Third, phonological awareness and orthographic skills in both grades play a crucial role at using sophisticated OPC rules during reading.

The present study implies that explicit phonological instruction using Tzuyin system in Taiwan not only strengthens the importance of phonological awareness in character reading, it also facilitates the development of orthographic knowledge when using OPC rules. As a result, $2^{\text {nd }}$ graders are generally proficient at using regular OPC rules. The sophisticated OPC rules is proposed as an important but not robust strategy for these grade 2 children due to an unforeseen deficiency in the experimental design, e.g., lacking sufficient learning trials for those test characters. Pedagogically, regular OPC is a default strategy to help second graders learning new characters, but they may need more explicit instructions and learning trials when adopting sophisticated OPC rules. Last but not the least, mapping a character with its pronunciation as a whole (i.e., at syllabic level) is also a crucial strategy for grade 2 children to learn to read new characters. 


\section{Appendices}

Three types of characters were employed to sort out the process of learning to read Chinese characters, namely: 1) same ideophonetic compounds by regular OPC rules;

2) tone- and onset-different ideophonetic compounds by sophisticated OPC rules, and 3) non-ideophonetic character by mapping as a whole, as illustrated in appendices below. 
Appendix 1 Same Ideophonetic Compounds-Regular OPC Rules

Clue Character Test Character Frequency Consistency Stroke Counts

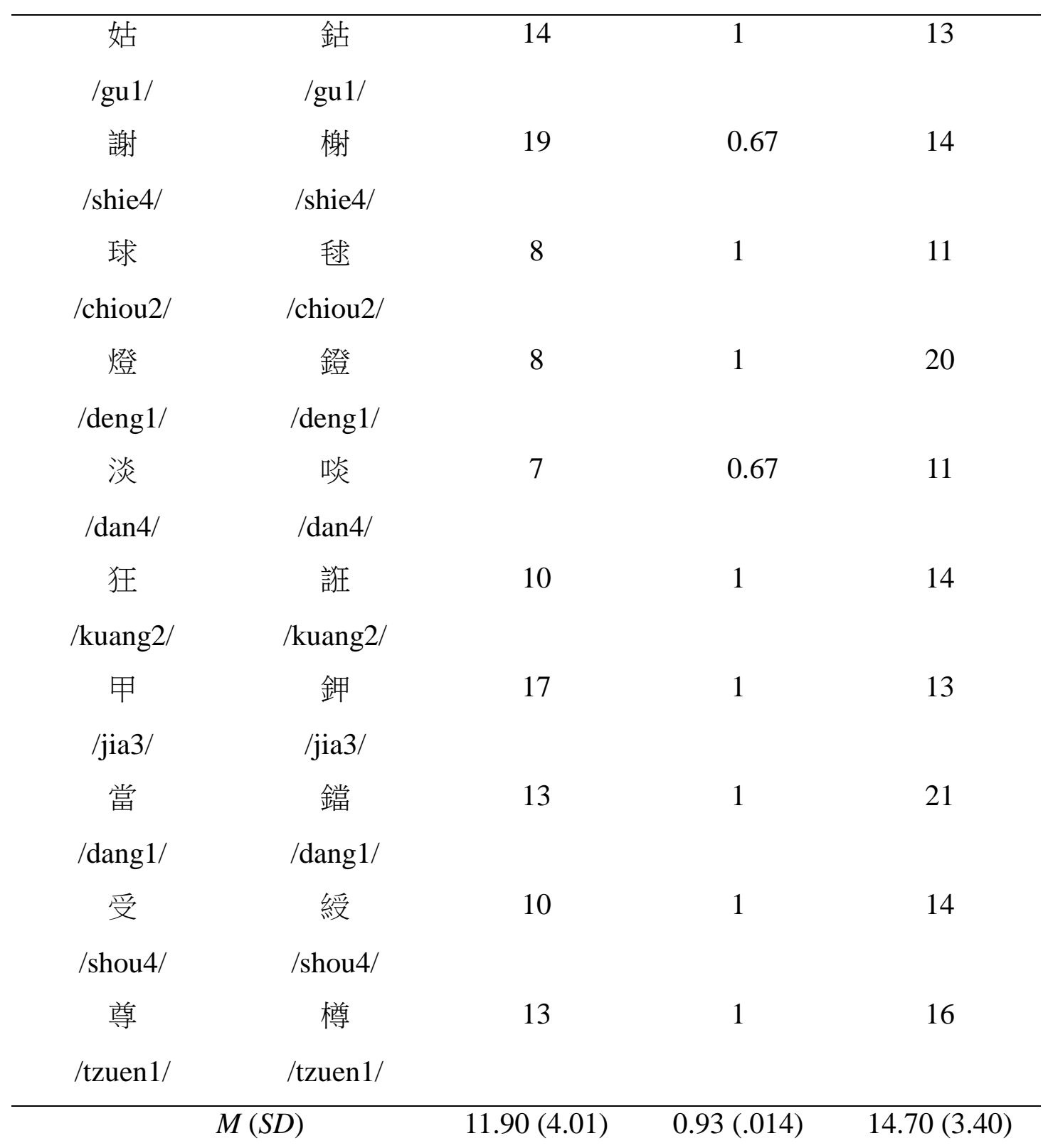


Appendix 2 Tone- and Onset-Different Ideophonetic Compounds - Sophisticated OPC Rules

\begin{tabular}{|c|c|c|c|c|}
\hline Clue Character & Test Character & Frequency & Consistency & Stroke Counts \\
\hline 姑 & 牯 & 10 & 1 & 9 \\
\hline /gu1/ & /gu3/ & & & \\
\hline 樓 & 鏤 & 13 & 1 & 18 \\
\hline /lou2/ & /lou4/ & & & \\
\hline 由 & 婇 & 18 & 1 & 12 \\
\hline /iou2/ & /iou4/ & & & \\
\hline 去 & 袪 & 12 & 1 & 10 \\
\hline /chu4/ & /chu1/ & & & \\
\hline 出 & 黜 & 10 & 1 & 17 \\
\hline /chu1/ & /chu4/ & & & \\
\hline 補 & 脯 & 18 & 0.5 & 11 \\
\hline /bu3/ & /fu3/ & & & \\
\hline 練 & 諫 & 21 & 0.5 & 16 \\
\hline /lian4/ & /jian4/ & & & \\
\hline 操 & 臊 & 7 & 0.5 & 17 \\
\hline /tsau1/ & /sau1/ & & & \\
\hline 羽 & 詡 & 12 & 0.5 & 13 \\
\hline /iu3/ & /shiu3/ & & & \\
\hline 內 & 蚋 & 19 & 0.3 & 10 \\
\hline /nei4/ & /ruei4/ & & & \\
\hline$M(S D)$ & & $14.0(4.67)$ & $0.73(0.29)$ & $13.3(3.40)$ \\
\hline
\end{tabular}


Appendix 3 Non-ideophonetic Characters-Mapping Strategy

\begin{tabular}{|c|c|c|c|}
\hline Clue Character & Test Character & Frequency & Stroke Counts \\
\hline & 禀 & 14 & 13 \\
\hline \multicolumn{4}{|c|}{ /bing3/ } \\
\hline & 整 & 13 & 15 \\
\hline \multicolumn{4}{|c|}{$/ \mathrm{li} 2 /$} \\
\hline & 卤 & 13 & 11 \\
\hline \multicolumn{4}{|c|}{ /lu3/ } \\
\hline & 麾 & 12 & 15 \\
\hline \multicolumn{4}{|c|}{ /huei1/ } \\
\hline & 摰 & 13 & 15 \\
\hline \multicolumn{4}{|c|}{ /j4/ } \\
\hline & 芯 & 16 & 16 \\
\hline \multicolumn{4}{|c|}{ /ruei3/ } \\
\hline & 鴣 & 15 & 14 \\
\hline \multicolumn{4}{|c|}{ /iuan1/ } \\
\hline & 摹 & 10 & 15 \\
\hline \multicolumn{4}{|c|}{$/ \mathrm{mo} 2 /$} \\
\hline & 㝥 & 16 & 12 \\
\hline \multicolumn{4}{|c|}{ /mei4/ } \\
\hline & 郝 & 13 & 11 \\
\hline \multicolumn{4}{|c|}{ /nan3/ } \\
\hline$M(S D)$ & & $13.50(1.84)$ & $13.70(1.83)$ \\
\hline
\end{tabular}




\section{References}

Anderson, R. C., Li, W., Ku, Y. M., Shu, H., \& Wu, N. (2003). Use of partial information in learning to read Chinese characters. Journal of Educational Psychology, 95(1), 52-57.

Carnine, D., Silbert, J., \& Kameenui, E. J. (1997). Direct instruction reading (3 ${ }^{\text {rd }}$ ed.). NY: Merrill.

Chan, L. (1996). Children learn to read and write Chinese analytically. Unpublished Doctor of Philosophy, Institute of Education. University of London, London.

Chan, L., \& Nunes, T. (1998). Children's understanding of the formal and functional characteristics of written Chinese. Applied Psycholinguistics, 19(1), 115-131.

Chan, C. K. K., \& Siegel, L. S. (2001). Phonological processing in reading Chinese among normally achieving and good readers. Journal of Experimental Child Psychology, 80(1), 23-43.

Chen, Y. P. (1993). Word recognition and reading in Chinese. Unpublished doctoral dissertation, University of Oxford, England.

Chow, B.W.-Y. (2014). The differential roles of paired associate learning in Chinese and English word reading abilities in bilingual children. Reading and Writing: An Interdisciplinary Journal, 27(9), 1657-1672.

CKCPG (1995). Mandarin Chinese character frequency list based on national phonetic alphabetic (95-101). Taipei: Institute of Information Science Academica Sinica.

Fang, S.-P., Horng, R.-Y., \& Tzeng, O. J.-L. (1986). Consistency effects in Chinese character and pseudo-character naming tasks. In H. S. R. Kao \& R. Hoosain (Eds.), Linguistics, psychology, and the Chinese language (pp. 11-22). Hong Kong: University of Hong Kong. 
Henry, L.A. \& Millar, S. (1991). Memory span increases with age: A test of two hypotheses. Journal of Experimental Child Psychology, 51(3), 459-484.

He, Y., Wang, Q., \& Anderson, R.C. (2005). Chinese children's use of subcharacter information about pronunciation. Journal of Educational Psychology, 97(4), 572579.

Ho, C. S.-H. \& Bryant, P. (1997a). Phonological skills are important in learning to read Chinese. Developmental Psychology, 33(6), 946-951.

Ho, C. S.-H. \& Bryant, P. (1997b). Learning to read Chinese beyond the logographic phase. Reading Research Quarterly, 32(3), 276-289.

Ho, C. S.-H., Ng, T.-T., \& Ng, W.-K. (2003). A "radical” approach to reading development in Chinese: The role of semantic radicals and phonetic radicals. Journal of Literacy Research, 35(3), 849-879.

Ho, C. S.-H., Wong, W. L., \& Chan, W. S. (1999). The use of orthographic analogies in learning to read Chinese. Journal of Child Psychology Psychiatry, 40(3), 393403.

Ho, C. S.-H., Yau, P. W.-Y., \& Au, A. (2003). Development of orthographic knowledge and its relationship with reading and spelling among Chinese kindergarten and primary school children. In C. McBride-Chang \& H.-C. Chen (Eds.), Reading development in Chinese children (pp. 51-71). London: Praeger.

Hu, C.-F. \& Catts, H. W. (1998). The role of phonological processing in early reading ability: what we can learn from Chinese. Scientific Studies of Reading, 2(1), 55-79.

Huang, P. J. (2003). 漢字教學的理論與實踐 [The theory and practice of teaching Chinese characters]. Taipei, Taiwan: Lexis Book.

Hung, L. Y. (1997).「漢字視知覺測驗」編製初步報告 [The construction of test of visual perception of Chinese characters]. Journal of National Taiwan Normal University: Education, 42, 59-73. 
Hung, L. Y. (2001). 漢字視知覺測驗 [The test of visual perception of Chinese character]. Taipei, Taiwan: Psychological publishing.

Huang, H. S. (2001)。 中文年級識字測驗 [The Chinese Character Reading Test]. Taipei, Taiwan: Psychological publishing.

Huang, H. S. \& Hanley, J. R. (1994). Phonological awareness and visual skills in learning to read Chinese and English. Cognition, 54(1), 73-98.

Huang, H. S. \& Hanley, J. R. (1997). A longitudinal study of phonological awareness, visual skills, and Chinese reading acquisition among first-graders in Taiwan. International Journal of Behavioral Development, 20(2), 249-268.

Li, H., Shu, H., McBride-Chang, C., Liu, H.Y., Xue, J. (2009). Paired associate learning in Chinese children with dyslexia. Journal of Experimental Child Psychology, 103(2), 135-151.

Li, W.S. \& Ho, C.S.H. (2011). Lexical tone awareness among Chinese children with developmental dyslexia. Journal of Child Language, 38(4), 793-808.

Lin, C.-H., \& Collins, P. (2012). The effects of L1 and orthographic regularity and consistency in naming Chinese characters. Reading and Writing: An Interdisciplinary Journal, 25(9), 1747-1767.

Lwu, L. \& Lyou, H. S. (1998). 修言丁畢保得圖畫詞彙測驗 [The peabody picture vocabulary test-revised in Mandarin]. Taipei: Psychological Publishing

McBride-Chang, C. \& Ho, C. S.-H. (2005). Predictors of beginning reading in Chinese and English: a two-year longitudinal study of Chinese kindergarteners. Scientific Studies of Reading, 9 (2), 117-144.

McBride-Chang, C., Tong, X.L., Shu, H., Wong, A.M.Y., Leung, K.W., Tardif, T. (2008). Syllable, phoneme, and tone: psycholinguistic units in early Chinese and English word recognition. Scientific Studies of Reading, 12(2), 171-194.

McBride-Chang, C. \& Zhong, Y. (2003). A longitudinal study of effects of 
phonological processing, visual skills, and speed of processing on Chinese character acquisition among Hong Kong Chinese Kindergartners. In C. McBrideChang \& H.-C. Chen (Eds.), Reading development in Chinese children (pp. 20-37). London: Praeger.

Pak, A. K. H., Cheng-Lai, A., Tso, I. F., Shu, H., Li, W., \& Anderson, R. C. (2005). Visual chunking skills of Hong Kong children. Reading and Writing: An Interdisciplinary Journal, 18(5), 437-454.

Qian, Y., Song, Y.-W., Zhao, J., Bi, H.-Y. (2015). The developmental trend of orthographic awareness in Chinese preschoolers. Reading and Writing: An Interdisciplinary Journal, 28(4), 571-586.

Shu, H., \& Anderson, R.C. (1997). Role of radical awareness in the character and word acquisition of Chinese children. Reading Research Quarterly, 32(1), 78-89.

Shu, H., Anderson, R. C., \& Wu, N. (2000). Phonetic awareness: knowledge of orthographic-phonology relationships in the character acquisition of Chinese children. Journal of Educational Psychology, 92(1), 56-62.

Shu, H., Peng, H., \& McBride-Chang, C. (2008). Phonological awareness in young Chinese children. Developmental Science, 11(1), 171-181.

Shu, H., \& Wu, N. (2006). Growth of orthography-phonology knowledge in the Chinese writing system. In P. Li, L. H. Tan, E. Bates, \& O. J. L. Tzeng (Eds.), The handbook of East Asian psycholinguistics (Vol. 1, pp. 103-113). New York: Cambridge University Press.

Siok, W. T. \& Fletcher, P. (2001). The role of phonological awareness and visualorthographic skills in Chinese reading acquisition. Developmental Psychology, $37(6), 886-899$.

Tsai, K.-C., \& Nunes, T. (2003). The role of character schema in learning novel Chinese characters. In C. McBride-Chang \& H.-C. Chen (Eds.). Reading 
development in Chinese children (pp. 109-126). London: Praeger.

Wang, C.-C., Hung, L.-Y., \& Chen, H.-F. (2007). The problem of the "Matthew Effects": Evidence from students with small character size. Bulletin of Special Education, 32(3), 1-16.

Wang, Y., \& McBride, M. (2014). Character reading and word reading in Chinese: unique correlates for Chinese kindergarteners. Applied Psycholinguistics, 37(2), 371-386.

Wang, Y., Yin, L., \& McBride, C. (2015). Unique predictors of early reading and writing: A one-year longitudinal study of Chinese kindergarteners. Early Childhood Research Quarterly, 32, 51-59.

Wei, T.-Q., Bi, H.-Y., Chen, B.-G., Liu, Y., Weng, X.-C., Taeko, N.W. (2014). Developmental changes in the role of different metalinguistic awareness skills in Chinese reading acquisition from preschool to third grade. PLoS ONE, 9(5), e96240.

Yu, S. -J. (1993). 瑞文氏彩色圖形推理測驗 [Raven's colored progressive matrices]. Taipei, Taiwan: Chinese Behavioral Sciences Corporation. 
Tables 
Table 1

Means (M), Standard Deviations (SD), Percentage Scores (\%), Chance Level and Reliability of the Tasks in Grades 1 and 2

\begin{tabular}{|c|c|c|c|c|c|c|c|}
\hline \multirow[b]{2}{*}{ Measures (Max. Score) } & \multicolumn{3}{|c|}{ Grade 1} & \multicolumn{3}{|c|}{ Grade 2} & \multirow{2}{*}{$\begin{array}{r}\text { T-Test } \\
\mathrm{T}(107)\end{array}$} \\
\hline & $M$ & $S D$ & $\begin{array}{c}\text { Percentag } \\
\text { e scores/ } \\
\text { chance } \\
\text { level }(\%)\end{array}$ & $M$ & $S D$ & $\begin{array}{c}\text { Percentage } \\
\text { scores/ } \\
\text { chance level } \\
(\%)\end{array}$ & \\
\hline Character Reading (200) & 26.1 & 13.95 & & 50.73 & 12.20 & & $25.57 * * *$ \\
\hline \multicolumn{8}{|l|}{ Phonological Awareness } \\
\hline Onset (20) & 9.83 & 4.05 & $49.15 / 25 \%$ & 10.43 & 4.11 & $52.15 / 25 \%$ & 1.81 \\
\hline Rime (20) & 8.81 & 3.50 & $44.05 / 25 \%$ & 9.81 & 4.03 & $49.05 / 25 \%$ & $3.60 * * *$ \\
\hline Tone (20) & 10.26 & 4.11 & $51.30 / 33 \%$ & 11.16 & 4.17 & $55.80 / 33 \%$ & $2.49 *$ \\
\hline \multicolumn{8}{|l|}{ Rudimentary } \\
\hline \multicolumn{8}{|l|}{ Orthographic Awareness } \\
\hline $\begin{array}{l}\text { Configuration Matching } \\
\text { (20) }\end{array}$ & 14.36 & 3.16 & $71.80 / 25 \%$ & 16.16 & 1.96 & $80.80 / 25 \%$ & $6.21 * * *$ \\
\hline $\begin{array}{l}\text { Structure Knowledge } \\
\text { (24) }\end{array}$ & 16.92 & 4.33 & $70.50 / 50 \%$ & 19.79 & 3.01 & $82.46 / 50 \%$ & $6.72 * * *$ \\
\hline Visual Matching (18) & 16.06 & 2.13 & $89.22 / 25 \%$ & 16.70 & 1.42 & $92.78 / 25 \%$ & $3.05 * *$ \\
\hline
\end{tabular}




$\begin{array}{lllllll}\text { Verbal IQ (PPVT) (125) } & 73.80 & 14.3 & & 85.70 & 14.7 & 10.19^{* * *} \\ \text { Non-Verbal IQ (RCPM) } & 35.02 & 6.64 & 55.59 & & & \\ (63) & & & & & & \end{array}$

Note. $\mathrm{N}=108 * p<.05 . * * p<.01 . * * * p<.001$ 
Table 2

The Correlation of the Variables at Grade 1 and Grade 2

\begin{tabular}{|c|c|c|c|c|c|c|c|c|c|c|c|c|c|c|c|c|}
\hline & 1 & 2 & 3 & 4 & 5 & 6 & 7 & 8 & 9 & 10 & 11 & 12 & 13 & 14 & 15 & 16 \\
\hline 1 Character & - & & & & & & & & & & & & & & & \\
\hline \multicolumn{17}{|l|}{ Reading 1} \\
\hline 2 Onset & $.31^{* * * *}$ & - & & & & & & & & & & & & & & \\
\hline \multicolumn{17}{|l|}{ Awareness 1} \\
\hline 3 Rime & $.43^{* * *}$ & $.56^{* * *}$ & - & & & & & & & & & & & & & \\
\hline \multicolumn{17}{|l|}{ Awareness 1} \\
\hline 4 Tone & $.31^{* * * *}$ & $.32^{* * *}$ & $.50^{* * *}$ & - & & & & & & & & & & & & \\
\hline \multicolumn{17}{|l|}{ Awareness 1} \\
\hline 5 Verbal IQ 1 & $.35^{* * *}$ & $.24^{*}$ & $.23^{*}$ & $.22^{*}$ & - & & & & & & & & & & & \\
\hline 6 Visual & .14 & $.20^{*}$ & $.21^{*}$ & .19 & $.27^{* * * *}$ & - & & & & & & & & & & \\
\hline \multicolumn{17}{|l|}{ Matching 1} \\
\hline $\begin{array}{l}7 \text { Configuration } \\
\text { Matching } 1\end{array}$ & $.24^{*}$ & $.23^{*}$ & \multicolumn{14}{|c|}{ Matching 1} \\
\hline $\begin{array}{l}8 \text { Structure } \\
\text { Knowledge } 1\end{array}$ & $.33^{* * * *}$ & $.48^{* * * *}$ & $.49^{* * * *}$ & $.30^{* * * *}$ & $.31^{* * * *}$ & -.03 & $.24^{*}$ & - & & & & & & & & \\
\hline 9 Character & $.71^{* * *}$ & $.36^{* * *}$ & $.49^{* * * *}$ & $.42^{* * *}$ & $.33^{* * *}$ & $.25^{* *}$ & $.26^{* * *}$ & $.30^{* * *}$ & - & & & & & & & \\
\hline \multicolumn{17}{|l|}{ Reading 2} \\
\hline $\begin{array}{l}10 \text { Onset } \\
\text { Awareness } 2\end{array}$ & $.24^{*}$ & $.65^{* * * *}$ & $.53^{* * *}$ & $.41^{* * *}$ & $.27^{* * * *}$ & $.27^{* * * *}$ & .19 & $.36^{* * * *}$ & $.31^{* * * *}$ & - & & & & & & \\
\hline
\end{tabular}




\begin{tabular}{|c|c|c|c|c|c|c|c|c|c|c|c|c|c|c|c|c|}
\hline 11 Rime & $.38^{* * * *}$ & $.59^{* * * *}$ & $.72^{* * * *}$ & $.49^{* * *}$ & $.32^{* * *}$ & $.27^{* * *}$ & $.25^{* *}$ & $.51^{* * * * *}$ & $.44^{* * * *}$ & $.64^{* * * *}$ & - & & & & & \\
\hline \multicolumn{17}{|l|}{ Awareness 2} \\
\hline 12 Tone & $.31^{* * *}$ & $.39^{* * *}$ & $.42^{* * *}$ & $.59^{* * *}$ & $.22^{*}$ & $.31^{* * *}$ & .18 & $.30^{* * *}$ & $.34^{* * *}$ & $.40^{* * *}$ & $.58^{* * *}$ & - & & & & \\
\hline \multicolumn{17}{|l|}{ Awareness 2} \\
\hline 13 Verbal IQ 2 & $.33^{* * *}$ & $.28^{* * *}$ & $.33^{* * * *}$ & $.23^{*}$ & $.65^{* * *}$ & $.35^{* * *}$ & .18 & $.40^{* * *}$ & $.30^{* * *}$ & $.28^{* * * *}$ & $.43^{* * *}$ & $.37^{* * * *}$ & - & & & \\
\hline 14 Visual & .09 & $.30^{* * *}$ & $.30^{* * *}$ & .17 & $.24^{*}$ & $.27^{* * *}$ & .16 & $.21^{*}$ & .16 & $.33^{* * *}$ & $.27^{* * *}$ & $.27^{* * * *}$ & .18 & - & & \\
\hline \multicolumn{17}{|l|}{ Matching 2} \\
\hline 15 Configuration & .13 & $.34^{* * *}$ & $.29^{* * * *}$ & .14 & .14 & $.31^{* * *}$ & $.39^{* * * *}$ & $.30^{* * *}$ & $.27^{* * *}$ & $.39^{* * *}$ & $.29^{* * *}$ & .13 & $.22^{*}$ & $.33^{* * *}$ & - & \\
\hline \multicolumn{17}{|l|}{ Matching 2} \\
\hline 16 Structure & $.22^{*}$ & $.40^{* * *}$ & $.47^{* * * *}$ & .18 & .16 & $.24^{*}$ & $.25^{* *}$ & $.35^{* * *}$ & $.33^{* * *}$ & $.25^{* *}$ & $.36^{* * *}$ & $.21^{*}$ & $.24^{*}$ & $.28^{* * *}$ & $.28^{* * *}$ & - \\
\hline \multicolumn{17}{|l|}{ Knowledge 2} \\
\hline 17 Non-Verbal & $.31^{* * * *}$ & $.39^{* * * *}$ & $.41^{* * * *}$ & .18 & $.38^{* * * *}$ & $.37^{* * *}$ & $.35^{* * * *}$ & $.32^{* * * *}$ & $.40^{* * *}$ & $.31^{* * * *}$ & $.45^{* * *}$ & $.26^{* *}$ & $.48^{* * * *}$ & $.20^{*}$ & $.26^{* *}$ & $.35^{* * * *}$ \\
\hline IQ in Grade 1 & & & & & & & & & & & & & & & & \\
\hline
\end{tabular}

Note. * $p<.05 ; * * p<.01 ; * * * p<.001$. 
Table 3

a. Hierarchical Regression Explaining Grade 1 Character Reading Predicted by the Sub-skill Variables in Grade 1

\begin{tabular}{|c|c|c|c|c|c|c|}
\hline Steps & Predictors & $R^{2}$ & $\Delta R^{2}$ & $\begin{array}{c}\Delta F \\
\text { change }\end{array}$ & $\beta$ & $t$ \\
\hline \multirow[t]{3}{*}{1} & Non-Verbal IQ & .157 & .157 & $6.47 * * *$ & & \\
\hline & Verbal IQ & & & & & \\
\hline & Visual Matching & & & & & \\
\hline \multirow[t]{3}{*}{2} & Rudimentary Orthographic Awareness & .207 & .050 & $3.2^{*}$ & & \\
\hline & Configuration Matching & & & & .12 & 1.17 \\
\hline & Structure Knowledge & & & & .20 & $1.95^{*}$ \\
\hline \multirow[t]{4}{*}{2} & Phonological Awareness & .262 & .105 & $4.79 * *$ & & \\
\hline & Onset & & & & .04 & .42 \\
\hline & Rime & & & & .27 & $2.31^{*}$ \\
\hline & Tone & & & & .10 & 1.02 \\
\hline
\end{tabular}

b. Hierarchical Regression Explaining Grade 2 Character Reading Predicted by the Sub-Skill Variables in Grade 2

\begin{tabular}{|c|c|c|c|c|c|c|}
\hline Steps & Predictors & $R^{2}$ & $\Delta R^{2}$ & $\begin{array}{c}\Delta F \\
\text { change }\end{array}$ & $\beta$ & $t$ \\
\hline 1 & Non-Verbal IQ & .179 & .179 & $7.55 * * *$ & & \\
\hline
\end{tabular}


Verbal IQ

Visual Matching

2 Rudimentary Orthographic Awareness

.224

.045

$2.98^{+}$

Configuration Matching

Structure Knowledge

2

Phonological Awareness

Onset

Rime

Tone

$.12 \quad 1.08$

c. Hierarchical Regression Explaining Grade 2 Character Reading Predicted by the Sub-Skill Variables in Grade 1

\begin{tabular}{llccccc}
\hline Steps & Predictors & $R^{2}$ & $\Delta R^{2}$ & $\Delta F$ & $\beta$ & $t$ \\
& & & \multicolumn{5}{c}{ change } \\
\hline 1 & Non-Verbal IQ & .200 & .200 & $8.69 * * *$ \\
& Verbal IQ & & & & \\
& Visual Matching & & & & & \\
& Character Reading Grade 1 & .551 & .351 & $80.46^{* * * *}$ & .57 & $7.59^{* * * *}$ \\
3 & Rudimentary Orthographic Awareness & .552 & .001 & 0.14 & & \\
& Configuration Matching & & & & .01 & 0.09 \\
& Structure Knowledge & & & & -.06 & -0.65
\end{tabular}


$4 \quad$ Phonological Awareness

\section{Onset}

Rime

Tone

alternatively

3 Phonological Awareness

Onset

Rime

Tone

$4 \quad$ Rudimentary Orthographic Awareness

Configuration Matching

Structure Knowledge
.592

.040

$3.21 *$

$\begin{array}{cc}.05 & 0.55 \\ .10 & 1.04 \\ .16 & 2.06^{*}\end{array}$

Note. $+p \simeq .05 ; * p<.05 ; * * p<.01 ; * * * p<.001$. 
Table 4

Scores (M) and Standard Deviations (SD) of Performances on Applying Different

Strategies to Learn Reading Novel Characters (Max. score $=10$ )

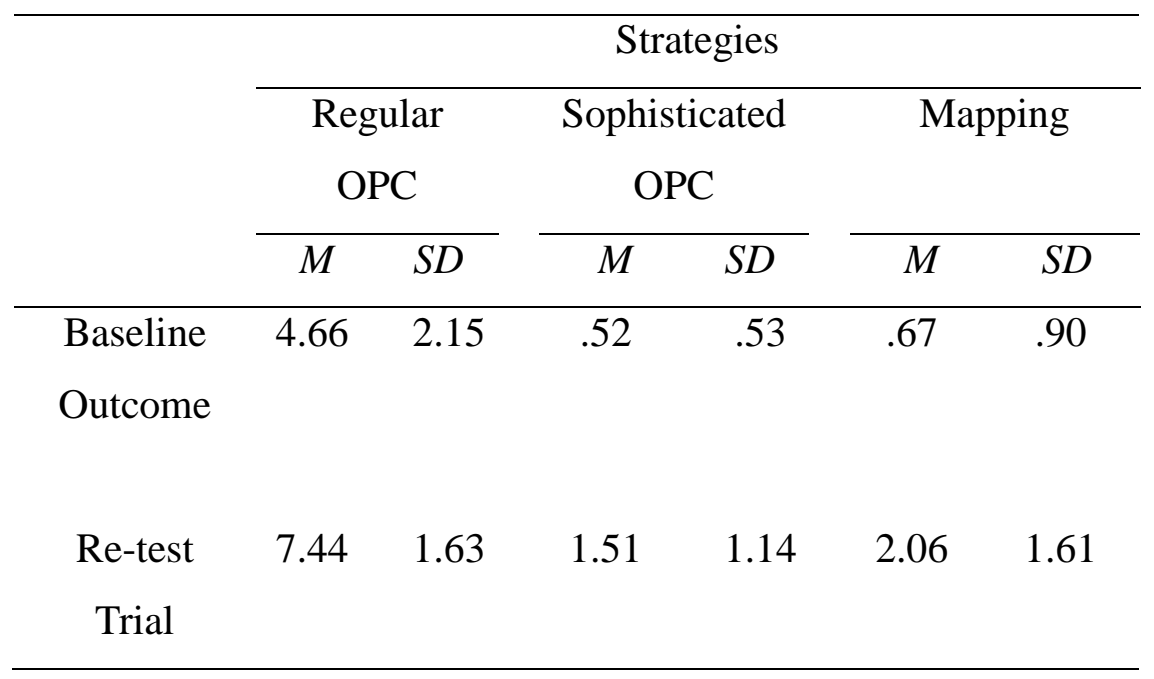


Table 5

Association of Performances on Applying Different Learning Strategies with Character Reading, Phonological Awareness, and Rudimentary Orthographic Awareness after Controlling for Non-verbal IQ and Baseline Performances ( $n=$ 108)

\begin{tabular}{|c|c|c|c|}
\hline & $\begin{array}{l}\text { Regular } \\
\text { OPC }\end{array}$ & $\begin{array}{l}\text { Sophisticated } \\
\text { OPC }\end{array}$ & $\begin{array}{l}\text { Mapping } \\
\text { Strategy }\end{array}$ \\
\hline \multicolumn{4}{|l|}{ Character reading } \\
\hline Grade 1 Character Reading & .05 & $.40 * * *$ & $.44 * * *$ \\
\hline Grade 2 Character Reading & .06 & $.40 * * *$ & $.49 * * *$ \\
\hline \multicolumn{4}{|l|}{ Phonological Awareness } \\
\hline Grade 1 Onset Awareness & .01 & .13 & .11 \\
\hline Grade 2 Onset Awareness & .16 & .16 & .15 \\
\hline Grade 1 Rime Awareness & .10 & $.33 * *$ & .18 \\
\hline Grade 2 Rime Awareness & .07 & $.31 * *$ & .18 \\
\hline Grade 1 Tone Awareness & .09 & $.29 * *$ & .09 \\
\hline Grade 2 Tone Awareness & .10 & .15 & .01 \\
\hline \multicolumn{4}{|l|}{ Rudimentary Orthographic } \\
\hline \multicolumn{4}{|l|}{ Awareness } \\
\hline Grade 1 Configuration Matching & .00 & .10 & .06 \\
\hline Grade 2 Configuration Matching & .03 & $.20^{*}$ & .12 \\
\hline Grade 1 Structure Knowledge & $.24 *$ & $.24^{*}$ & .15 \\
\hline Grade 2 Structure Knowledge & .01 & $.22 *$ & .07 \\
\hline
\end{tabular}

Note. ${ }^{*} p<.05 ; * * p<.01 ; * * * p<.001$. 